\title{
Osteogenesis imperfecta type 2
}

INSERM

\section{Source}

INSERM. (1999). Orphanet: an online rare disease and orphan drug data base.

Osteogenesis imperfecta type 2. ORPHA:216804

Osteogenesis imperfecta type II is a lethal type of osteogenesis imperfecta (Ol; see this term), a genetic disorder characterized by increased bone fragility, low bone mass and susceptibility to bone fractures. Patients with type II present multiple rib and long bone fractures at birth, marked deformities, broad long bones, low density on skull X-rays, and dark sclera. 